\title{
LENIN: DO ANO REVOLUCIONÁRIO À CISÃO DO POSDR (1905-1911)
}

\author{
LENIN: DEL AÑO REVOLUCIONARIO A LA ESCISIÓN DEL POSDR (1905-1911)
}

LENIN: FROM THE REVOLUTIONARY YEAR TO THE POSDR SPLIT (1905-1911)

DOI: http://dx.doi.org/10.9771/gmed.v12i2.38677

Marcos Del Roio ${ }^{1}$

Resumo: este artigo tem a intenção de apresentar a concepção teórica e política de Lênin no período transcorrido entre 1905 e 1911, do ano revolucionário até a completude da cisão entre bolcheviques e mencheviques e a superação da cisão latente entre os bolcheviques. A interlocução de Lênin e Bogdánov é acompanhada com prioridade no ambiente intelectual de crise e diversificação ideológica.

Palavras-chave: Lênin. Bogdánov. Bolcheviques. Marxismo. Cultura proletária.

Resumen: Este artículo pretende presentar la concepción teórica y política de Lenin en el período comprendido entre 1905 y 1911, desde el año revolucionario hasta la culminación de la escisión entre bolcheviques y mencheviques y la superación de la escisión latente entre bolcheviques. La interlocución de Lenin y Bogdánov se sigue con prioridad en el entorno intelectual de crisis y diversificación ideológica.

Palabras clave: Lenin. Bogdánov. Bolcheviques. Marxismo. Cultura proletaria.

Abstract: this paper aims at presenting Lenin's theoretical and political conception from the period that goes from 1905 to 1911, from the revolutionary year to the complete split between Bolsheviks and Mensheviks and the overcome of the latent split among the Bolsheviks. The interaction between Lenin and Bogdanov is followed as a priority in the intellectual environment of crisis and ideological diversity.

Keywords: Lenin. Bogdanov. Bolshevism. Marxism. Proletarian culture.

\section{Introdução}

Em dezembro de 1910, Lênin escreveu que o período iniciado com a revolução de 1905, mostrou mudanças significativas na situação social e política do Império russo. Dizia então que “diante de nós resaltam em seguida os dois triênios em que se divide esse período: um termina pelo verão de 1907; o outro acaba no verão de 1910” (LÊENIN, [23/12/1910], t. III, 1976, p. 408).

Lênin afirma ainda que todo o período é coberto pela evolução capitalista, apenas que a primeira fase foi de avanço, no sentido de que todas as classes se organizaram e se expressaram por meios políticos e culturais, mas a segunda fase foi de quase estagnação e de crise do marxismo. Acompanhar o pensamento de Lênin, nesses dois triênios, tal como sugestão dele próprio, é o objetivo deste artigo, ainda que transborde até janeiro de 1912. 
No entanto, em relação ao ano abertamente revolucionário de 1905 , que poderia ser objeto de um artigo (ou muitos) isolado, a abordagem será rápida e restrita apenas a expor a teoria da revolução formulada por Lênin. As divergências com os mencheviques - a outra vertente do marxismo russo - terá que ser tocada, assim como as divergências entre os próprios bolcheviques. No primeiro triênio as diferenças foram de concepção política, de ação política, enquanto no momento seguinte foram discussões de esclarecimento filosófico e teórico que vieram a predominar - com o particular destaque para a elaboração de Bogdánov -- sempre com o escopo de orientar a linha estratégica da luta revolucionária.

\section{O triênio do avanço}

O ano revolucionário de 1905 começou com a revolta dos trabalhadores, mas logo a burguesia assumiu a direção do processo. As classes sociais haviam se organizado em partidos nos anos anteriores, um sinal a mais de que a revolução burguesa estava próxima. O POSDR - Partido Operário Social Democrata da Rússia - estava, porém dividido nas vertentes conformadas no II Congresso, de 1903. Em meio à revolução, a fração bolchevique realizou um III Congresso do Partido, enquanto que os mencheviques realizaram conferências, cada grupo coerente com a concepção de partido que alimentavam. A coerência de ambos os grupos se mostrou também em relação à teoria da revolução e a tática da qual era decorrência.

De maneira muito sintética pode-se dizer que o ponto de partida de ambas a frações e talvez o único consenso fosse que a Rússia vivia o momento da revolução burguesa, a qual, por suposto, deveria ser uma revolução democrática, que instauraria as liberdades políticas, ou seja, as liberdades burguesas. Mas as diferenças sobre a tática e os objetivos eram intransponíveis. A primeira e essencial diferença era sobre o conceito de revolução burguesa.

Para os mencheviques a revolução burguesa deveria propulsionar o capitalismo na Rússia com a criação de um Estado democrático liberal, no qual houvesse liberdade de organização política e cultural. A burguesia, com respaldo da pequena burguesia, deveria dirigir o processo e configurar as novas instituições. A classe operária, por sua vez, deveria apoiar a burguesia com eventuais acordos com os liberais, mas não participar de eventual governo provisório de coalizão. Se colocar, em vez disso, estrategicamente como nova oposição, que se fortaleceria na medida em que as lutas econômicas se fizessem mais políticas, que a vida civil de diversificasse com formas de autogoverno revolucionário, a exemplo dos soviets, que a presença no parlamento se fizesse mais presente. Um POSDR de massas e forte nas instituições democráticas poderia então ser capaz de propor a revolução socialista, contando com uma classe operária mais numerosa e educada.

Os bolcheviques entendiam que uma revolução burguesa significa desenvolvimento das forças produtivas, industrialização e urbanização, além de elevação cultural e generalização do estatuto da cidadania dentro de um Estado democrático. $\mathrm{Na}$ particularidade do desenvolvimento do 
capitalismo na Rússia, o processo revolucionário deveria ser conduzido pelo proletariado industrial e não pela burguesia, desde que essa era estruturalmente frágil por ter nascido por influxo do Estado absolutista e contar com restrita base de sustentação de massa, o que a levaria a alguma forma de acordo com a nobreza e o regime czarista.

O proletariado, por sua vez, para ter sucesso, teria que se apoiar na massa camponesa para conseguir instaurar, por meio de uma insurreição armada, a república democrática, na forma de uma ditadura democrática do proletariado e do campesinato. Essa seria o caminho pelo qual a revolução democrática poderia ser levada até o fim, ou seja, ultrapassaria os limites demarcados por uma democracia burguesa. Lênin explicita com muita clareza a leitura que tinha do processo revolucionário na Rússia:

O proletariado deve levar até o fim a revolução democrática, atraindo as massas camponesas, para esmagar pela força a resistência da autocracia e paralisar a instabilidade da burguesia. O proletariado deve levar a cabo a revolução socialista atraindo a massa dos elementos semiproletários da população, para romper pela força a resistência da burguesia e paralisar a instabilidade dos camponeses e da pequena burguesia (LÊNIN, [14/09/1905] T. III, 1976, p. 85-86).

Sempre em setembro de 1905, Lênin reafirma essa visão estratégica (que será enfim vitoriosa em 1917):

Da revolução democrática começaremos de imediato a passar, exatamente na medida das nossas forças, das forças do proletariado consciente e organizado, começaremos a passar à revolução socialista. Nós somos pela revolução ininterrupta. Nós não nos firmaremos no meio do caminho (LÊENIN, 1905 apud STRADA, 1979, p. 471).

De fato, como antecipara Lênin, em fins de 1905, com a repressão generalizada contra o movimento revolucionário, a burguesia liberal e o regime czarista chegaram a um acordo que implicava a abertura de uma Câmara representativa - chamada Duma - que comportaria os interesses da burguesia. No entanto, a movimentação revolucionaria continuaria até meados de 1907.

No mês de abril de 1906, em Estocolmo, realizou-se o IV congresso do POSDR. Nesse congresso participou o conjunto da socialdemocracia russa, motivo pelo qual ficou conhecido como congresso de unificação. Foi, no entanto, o congresso no qual -- por meio de intenso e acalorado debate -- se explicitaram as diferenças entre as duas vertentes do marxismo russo.

A discussão foi muito acesa já em torno do programa agrário a ser adotado pelo partido. Enquanto os mencheviques entendiam que se devesse passar a questão da terra aos governos locais, Lênin e os bolcheviques defendiam a nacionalização da terra. Esse programa tinha implicações claras com a política de alianças a ser empreendida. Os mencheviques pretendiam alguma forma de acordo com a burguesia liberal para encaminhar o processo de democratização (burguesa). Os camponeses, segundo pensavam os mencheviques, não seriam aliados confiáveis, pois poderiam vir a ser a base de algum tipo de novo despotismo. O contraste não poderia ser maior, já que os bolcheviques pensavam se aproximar dos socialistas revolucionários (neo narodiniks) como meio da selar a aliança operária 
camponesa e preparar a insurreição popular armada, a qual, vitoriosa, instauraria a ditadura democrática do proletariado e do campesinato.

A mobilização popular era intensa e a cena política incerta. A Duma foi eleita com em maio de 1906 com uma maioria de liberais e com a oposição nucleada no Trudovik (Grupo do Trabalho), o Czar Nicolau II nomeou Stolypin como primeiro-ministro em substituição a Witte. A política governamental procurou estimular a evolução do capitalismo na Rússia, em particular no campo, o que fez surgir um significativo proletariado rural.

Em fevereiro de 1907, assumiu a II Duma e em abril, um ano depois do anterior, desta vez em Londres, se realizava o V congresso do POSDR, ao qual se seguiu a definitiva divisão do partido e o período de estagnação do movimento revolucionário. Vale lembrar duas questões muito importantes sobre as quais Lênin teve que mudar de opinião e se aproximar dos mencheviques. Uma delas foi sobre a participação do partido nas eleições, para as quais de inicio defendia o boicote; a outra foi sobre as chamadas instituições de autogoverno, como eram os soviets -- que surgiram com influxo da área menchevique -- que Lênin contrapôs a definição de instituições de poder (STRADA, 1979, p.488-489).

Outra acusação voltada a Lênin foi o apoio que ofereceu a ações armadas em 1906, o que marcava a aproximação com os socialistas revolucionários. Enfim, para Lênin e os bolcheviques essencial era a aliança com o campesinato e com quem o representasse, enquanto que os mencheviques preferiam fazer acordos com os representantes da burguesia liberal. A concepção marxista dos bolcheviques entendia que a revolução deveria ser feita a partir da particularidade histórica da Rússia e os mencheviques entendiam que a ocidentalização da Rússia era o escopo a ser alcançado.

\section{O triênio de refluxo}

O segundo triênio da conjuntura perscrutada por Lênin, que começa em meados de 1907, é então marcada pela repressão impiedosa, por medidas de estimulo a acumulação do capital, pela fragmentação da socialdemocracia russa e pelo afastamento dos intelectuais frente ao movimento popular e ao marxismo. Foi um momento de retirada para a vida privada e, ao mesmo tempo, uma revivescencia das filosofias idealistas. Grande repercussão tiveram as teses de Ernst Mach e Richard Avenarius, inclusive entre os marxistas revolucionários, os que produziram, por exemplo, o livro Ensaios sobre a filosofia do marxismo. Houve quem aderisse ao liberalismo e quem se encontrasse no cristianismo. Talvez a expressão mais clara desse movimento dos intelectuais tenha sido o livro Vekhi (Guinada), publicado em 1909, contendo ensaios de sete diferentes autores, cujo objeto era precisamente a questão da intelectualidade russa (STRUVE, PIOTR et al., [1909], 1990).

A situação de Lênin -- que qualifica essas manifestações intelectuais como revisionistas e reacionárias -- é bastante difícil, com risco mesmo de isolamento político. Os mencheviques, ainda 
que bastante desarticulados, investem bastante na representação política parlamentar e uma parte substantiva dos bolcheviques se apõe de modo terminante. A oscilação de Lênin quanto a essa questão, deixou-o em situação tão difícil que levou toda essa fase por ele mesmo identificada como de quase estagnação para ser superada. Era preciso, sempre segundo Lênin, combater o revisionismo de direita (menchevique) e de esquerda (dentro do próprio bolchevismo). Nessa nova fase de derrota, a luta ideológica no seio do movimento operário e do marxismo passava a ser crucial. Era preciso defender os fundamentos do marxismo.

Em pequeno artigo datado de abril de 1908, Marxismo e revisionismo, Lênin aborda essa questão de um modo bastante sintético, apenas como que colocando o problema na mesa. Uma síntese, porém exata, que apresenta a primeira fase do marxismo, quando se formou e se consolidou a custa da derrota de uma série de outras ideologias presentes nos albores do movimento operário e também de outras de origem burguesa, que buscavam influenciar a classe operária, principalmente em seguida a Comuna de Paris. No entanto, batidas essas ideologias, a partir dos anos 90 do século XIX, com o aparecimento do revisionismo de Bernstein,

mudaram as formas e os motivos da luta, mas essa continuou. E o segundo meio século de existência do marxismo (década de noventa do século passado) começou com a luta se uma corrente antimarxista no seio do próprio marxismo (LÊENIN, [16/04/1908] t. III, 1976, p. 299).

O fundamento teórico do revisionismo, como Lênin observa, encontra-se no "retorno a Kant", promovido na ciência elaborada na vida acadêmica. De fato, na virada do século XIX para o século XX, houve um resgate do kantismo e do idealismo filosófico com o fito de se opor ao positivismo, ao naturalismo e ao marxismo (em geral visto como uma teoria mecanicista). A crítica feita pelos revisionistas alemães ao marxismo, segundo Lênin, se opunha à dialética de Hegel e Marx, como justificativa para voltar a Kant.

Lênin passa rapidamente pelas teses revisionistas relativas à economia política, mas a chave de torno é a ideia do arrefecimento da luta de classes e o parlamento visto como ambiente de solução dos conflitos sociais. Para Lênin, a raiz do revisionismo encontra-se nos elementos da pequena produção mercantil que se aproximam da classe operária e do partido operário, de modo que "é completamente natural que a mentalidade pequeno-burguesa irrompa de novo, uma ou outra vez, nas fileiras do partido operário" (LÊNIN, t III, 1976, p. 306).

Ainda que tenha entrado em aberto conflito contra Plekhanov em relação à linha política a ser posta em prática pela socialdemocracia russa, Lênin manteve-se próximo ao velho militante na defesa do marxismo contra os revisionismos, mesmo aquele que eclodiu com força entre os bolcheviques. Em relação às concepções filosóficas, Lênin tinha a mesma opinião que a relativa à questão religiosa: cada um poderia alimentar a sua, visto que a prioridade era o acordo sobre a política revolucionária (claro que se trata também isso de uma tática política!). Assim que Lênin 
compartilhou com Alexendr Bogdánov a direção da fração bolchevique desde 1904, quando da experiência do periódico Vperiod (Avante).

Nesses anos, de 1904 a 1906, Bogdánov redigiu a trilogia que consolidou a sua visão filosófica, nomeada como Empiriomonismo, devedora de Marx e de Mach, segundo o autor. Uma concepção que sem dúvida pode ser qualificada como revisionista por refutar a dialética e encontrar insuficiências na obra marxiana, em particular no referente a teoria do conhecimento. Bogdánov concebe o mundo existente como o caos que se organiza a partir das sensações humanas, a partir da forma em que os homens se adaptam na luta contra a resistência que encontra no mundo.

A natureza seria então o que resiste ao homem e o trabalho o meio de enfrentar essa resistência, o qual teria na técnica (e na ciência) o seu instrumento. Essa relação do homem, por meio de suas sensações, com o mundo, se altera com o passar do tempo, segundo as diferentes formas sociais, as quais tem um acúmulo técnico diferente e uma representação do mundo também diferente.

O interlocutor de Bogdánov, em princípio, era Plekhanov e sua filosofia materialista. Bogdánov pretendia, por seu verso, superar a antiga divisão entre materialismo e idealismo na Filosofia e propor uma "filosofia da ação", ainda que seus críticos tenham observado na sua elaboração um idealismo subjetivo.

Essa concepção filosófica tinha claras implicações políticas, pois deduzia haver uma ciência da burguesia e uma ciência do proletariado, fundamentada essa no trabalho, nas sensações que emergem do ato de trabalhar e reconfigurar a natureza. Na perspectiva revolucionária seria então essencial educar os trabalhadores, elevar o seu padrão científico e cultural a fim de que pudessem criar uma cultura proletária e reordenar a produção desde os seus próprios interesses e conforme a técnica desenvolvida (TOLEDO, 2019).

\section{A disputa ideológica entre os bolcheviques}

A discórdia política entre os bolcheviques teve início com a dissolução da II Duma, com o problema de qual seria a posição a ser tomada nas eleições seguinte para a III Duma. Para Lênin, aquele verão de 1907 aparecia como já marcado pela estagnação da luta revolucionária e a ocupação de espaços políticos era da maior importância. Nisso se destacava a eleição de uma bancada no parlamento. Um grupo parlamentar que fizesse dura oposição à monarquia e que denunciasse a falsidade do seu constitucionalismo parlamentar era importante para educar as massas, mas também para preservar a organização partidária, cujo principal objetivo continuava a ser a derrubada do regime e a conquista do poder político. Para Bogdánov e seus seguidores, como Lunacharvsky, Krasin e Gorki, a importância se deslocava para a educação do proletariado com completo afastamento da luta institucional. Uma ampla reforma cultural do proletariado, que deveria se imbuir de disciplina e organização, precederia a questão do poder político (SCHERRER, 1979). 
Como a decisão foi pela participação na eleição e na Duma, a discussão se transferiu para outro plano. Configurou-se de modo mais claro a divisão entre os bolcheviques. Lênin decidiu participar assiduamente na vida parlamentar ao modo de um assessor, mas houve aqueles favoráveis a retirada dos deputados (otozvat) e outros, como Bogdánov e seu grupo intelectual, defendiam agora que os deputados deveriam ser obrigados a seguir a linha política do partido (ficaram conhecidos como ultimatistas).

A essa altura a luta entre Lênin contra o bolchevismo de esquerda já havia se desencadeado. Em 1908, Bogdánov foi primeiro afastado do comitê de redação do Proletário, periódico da fração bolchevique, em seguida do comitê de finanças, juntamente com Krasin.

Ainda em 1908, Bogdánov publicou um livro de ficção, chamado $A$ estrela vermelha, no qual expos como concebia o comunismo. Nesse pequeno volume mostra a importância da organização e da ciência para que os homens se adaptem às condições oferecidas pelo ambiente natural. A história narra a viagem de um humano ao planeta Marte, que já havia realizado o comunismo havia três séculos, impulsionados por grave crise ambiental derivada do anterior uso irracional da água. A questão da organização e do planejamento é bastante enfatizada (TOLEDO, 2019).

Nesse mesmo ano de 1908, Bogdánov compôs o grupo que publicou o livro coletânea Ensaios sobre a filosofia do marxismo. Outros três livros da mesma área intelectual revisionista vieram a lume em poucos meses. A ação política cultural de Bogdánov e seus companheiros foi muito intensa também nos anos seguintes. Foi lançado um periódico da esquerda bolchevista, que retomava o nome de outro do mesmo nome, de 1904, Vperiod. Sempre em 1909, foram organizados dois cursos de formação, um em Capri, onde residia Gorki, e outro em Bologna.

Entre os mencheviques se difundia a ideia de que não haveria necessidade de um partido operário na circunstancia de recrudescimento do czarismo. Tratava-se de respaldar os liberais e seria necessário esperar outro momento para que o partido operário ressurgisse. Muitos deles também haviam embarcado nas tendências revisionistas, inclusive aquela inspirada na filosofia da ciência de Ernst Mach.

Lênin entendeu que essa ofensiva ideológica dos bolcheviques de esquerda precisava ser contida, inda mais que convergia com o liquidacionismo menchevique, compondo um ambiente intelectual revisionista que poderia ser fatal para a luta revolucionária. Para completar, deve ser lembrado que em 1909 ainda apareceu outra coletânea, parcialmente composta por autores que haviam migrado para o liberalismo, a obra Vecki (A guinada).

Em tal situação era decisivo reafirmar a importância do partido revolucionário e do marxismo definido conforme os textos de Marx e Engels. Em fevereiro de 1909, em seguida a uma conferência do POSDR realizada no final do ano, Lênin procura esclarecer a visão que tinha do caminho a ser seguido, considerando que desde o V congresso (1907) a socialdemocracia russa havia 
se dispersado e se perdido, incluindo os próprios bolcheviques. A crise do partido era orgânica pelo seu caráter.

E esta causa fundamental reside na depuração do partido operário de elementos intelectuais e pequenos burgueses vacilantes que aderiram ao movimento operário, principalmente, com a esperança de um triunfo próximo da revolução democrática burguesa e que não puderam se manter firmes no período de reação (LÊNIN, [10/02/1909] III, 1976, p. 349).

Mas a crise era também ideológica e política. Era necessário consolidar a posição de que o partido se move orientado pelo marxismo revolucionário e que tem uma clara linha de ação política. A necessidade de construir células em lugares de trabalho seria decisiva para que o partido, enquanto organização política e ideológica, ganhasse força. Lênin chama a atenção para a debilidade dos resultados alcançados pela monarquia para desenvolver o capitalismo e se fazer uma monarquia burguesa, considerando a resistência da nobreza feudal e a tibieza da burguesia. De fato, a conjuntura era de progressiva desagregação do Estado e do feudalismo, na qual a classe operária deveria se preparar para a tomada do poder. $\mathrm{O}$ acordo alcançado na conferencia clamava também por encontrar uma adequada relação entre trabalho legal e ilegal e também "o reconhecimento da necessidade de utilizar a tribuna da Duma e elaboração de indicações reitoras precisas para a nossa minoria da Duma, em relação com a crítica direta de seus erros (LÊENIN, p.350).”

A divergência entre Lênin e Bogdánov girava em torno de duas questões correlatas: Lênin notava que a fase era de estagnação da luta e que a política de Stolypin fazia avançar o capitalismo e permitia uma ação política no parlamento. Bogdánov entendia que o partido deveria se organizar e educar para uma nova insurreição para quando a ocasião se apresentasse. O desprezo pela atuação parlamentar era completo, ainda que concordasse que a bancada parlamentar devesse ser subordinada à direção partidária.

A ruptura já estava clara no começo de 1909, mas só na metade do ano se tornou pública. Uma reunião realizada em Paris, em junho de 1909, fechou a contenda. Toda a esquerda foi excluída da fração bolchevique. À critica política ideológica se agrega agora uma séria critica filosófica. Os bolcheviques de esquerda fundaram o Vperiod como órgão de cultura proletária e colocaram em prática a ideia da escola superior socialdemocrata, em Capri (agosto-dezembro de 1909) e em Bologna (novembro de 1910 a março de 2011).

Bogdánov, num clima de exacerbação das diferenças, afirma que "o bolchevismo não é um simples fenômeno político, mas é também um movimento sociocultural” e explica em seguida que "Um pressuposto implícito do bolchevismo é portanto a ideia da criação imediata, no âmbito da sociedade atual, de uma grande cultura proletária, mais forte e harmoniosa que a cultura das classes burguesas que estão se enfraquecendo, infinitamente mais livre e criativa (BOGDÁNOV apud SCHERRER, 1979)."

Para Bogdánov a conquista da hegemonia tinha um significado diferente do entendimento de Lênin. Como Lênin priorizava a derrubada da autocracia e a instauração de uma república 
democrática, sua noção de hegemonia era estritamente política e ideológica, i.é, o partido político marxista seria o condutor da luta operária. Hegemonia para Bogdánov implicava um vasto processo de criação de uma nova cultura, de uma nova organização da experiência, de uma forma de ver e pensar o mundo, de criação de novas imagens, de estabelecer novas relações sociais. Essa oposição pode simplificar as diferenças entre esses autores, mas indica como havia uma discordância clara quanto à estratégia da revolução socialista. A inspiração soreliana do grupo do Vperiod é bastante perceptível, principalmente em Lunacharvisky.

\section{A disputa filosófica}

Em 1908, Lênin despendeu muito do seu tempo em bibliotecas a estudar para a produção do livro Materialismo e empiriocriticismo: notas críticas sobre uma filosofia reacionária, que foi publicado em 1909. Lênin mergulhou efetivamente na bibliografia das décadas precedentes para se apropriar do debate que ocorria na filosofia das ciências naturais e na teoria do conhecimento. Pelo que percebia, também na Rússia, frente o avanço do positivismo e do naturalismo, concepções neokantistas vinham se difundindo, até mesmo a chegar num evidente misticismo. A gravidade maior desse movimento de ideias é que se introjetava também no marxismo. Diferente do que pensava até alguns anos atrás, Lênin defendia agora a concepção de que a unidade partidária deveria ser consolidada com o reconhecimento por toda a militância do que seriam os fundamentos do marxismo. Naquele mesmo ano de 1908, apareceu o livro de G. Plekhanov, Questões fundamentais do marxismo, o qual, sem dúvida, serviu como importante referencia para a empreitada de Lênin, como a demonstrar a riqueza da produção e da polêmica ideológica daqueles anos (PLEKHANOV, 1956).

Como Lênin, Plekhanov entendia ser da maior importância a compreensão do marxismo como filosofia materialista e também a importância do partido operário. Essas genéricas concordâncias possibilitaram uma aproximação entre esses destacados militantes até 1912, quando Lênin decidiu-se pela completa ruptura com os mencheviques. Importante então dizer que a obra de Lênin, Materialismo e Empirocriticismo tem um escopo político imediato muito claro, que é o de derrotar o bolchevismo de esquerda.

O interesse nuclear de Lênin é então o de demonstrar como as concepções filosóficas de Mach e Avenarius, são caudatárias de formulações filosóficas do século XVIII inglês, de Berkeley e Hume, e também de Kant, que são, enfim, filosofias idealistas. Essas ideias tiveram muita influencia na intelectualidade russa e até mesmo no interior do próprio marxismo, com destaque para a tendência do Vperiod, o bolchevismo de esquerda, com Bogdánov, Lunacharski e outros.

Lênin também demarca o materialismo moderno como originado na França, com Diderot como exemplo. Quanto ao debate mais contemporâneo, Lênin invoca uma maioria de autores alemães, ingleses e russos na sua crítica. Os defensores do materialismo, com os quais Lênin se 
associa, são Feuerbach e principalmente Engels. Aqui já se pode antecipar que a concepção materialista de Lênin deve muito ao mestre Plekhanov e a Engels.

O materialismo é a concepção filosófica que entende que a existência do ser precede a consciência do ser, que tudo que existe é constituído de matéria, que a matéria existe no espaço e no tempo e que está sempre em movimento. A matéria compõe a realidade objetiva, que se reflete na consciência do homem, localizada no cérebro, e permite o conhecimento da realidade por meio da observação e da experiência, o que faz a pré-existente coisa em si se transformar em coisa para nós. A ciência é então um movimento de busca da verdade comprovada. Para Lênin, então, o avanço da ciência torna possível enfrentar outras formas de ver e interpretar o mundo, que não são capazes de apreender a realidade objetiva por meio de aproximações que buscam a verdade. A referência é a religião e as filosofias idealistas, ou seja, as concepções de mundo que entendem que a consciência ou ideia do ser precede a existência concreta do próprio ser, quando não que o mundo é apenas uma projeção das sensações humanas. Para Lênin essas concepções seriam falsas e produtos da alienação em relação a verdade estabelecida pela ciência. Nota-se o relativo desprezo de Lenin em relação a outras formas de apreensão do mundo produzidas por outras culturas humanas de outros tempos / outros espaços.

Para Bogdánov, cada forma social se apropria do mundo de modo particular e tem também a sua verdade particular expressa em representações. Assim que mito, religião, ciência são formas ideológicas adaptadas a diferentes condições técnicas que enfrentam determinado ambiente natural, aquele que impõe resistência ao labor humano. A ciência existente seria então uma ciência burguesa, já que orientada para os fins da hegemonia da burguesia na vida social. A tendência da Bogdánov a criar um vínculo estreito, quase a confundir sujeito e objeto, faz com que a objetividade seja produto da subjetividade e daí o idealismo filosófico duramente denunciado por Lênin.

Interessante notar como Lênin enfatiza com muita força a questão do materialismo e praticamente deixa de lado o problema da dialética entre sujeito e objeto. A teoria do reflexo corre o risco de diminuir drasticamente a concepção a qual o homem transforma a o mundo e a si mesmo na medida em que o conhece, na medida em que dele se apropria. O resultado é que Lênin acaba por subestimar a questão filosófica mais essencial que é a práxis transformadora, a projeção, o programa. Lênin praticamente se limita a dizer que a natureza se reflete na mente do homem no processo de conhecimento da realidade objetiva, quase a separar sujeito e objeto (LÊNIN, t.IV, 1976, p. 1-365).

Passado cerca de um ano da conferencia partidária de dezembro de 1908, Lênin recorda como os dois anos precedentes foram cobertos por disputas políticas e ideológicas (e filosóficas). A avaliação agora é que o partido chegou a um acordo sobre a fundamental, mesmo que diferenças e tendências permaneçam. As questões fundamentais eram "sobre a apreciação do momento atual e as tarefas políticas do proletariado; sobre a política orgânica do partido e a atitude diante da minoria socialdemocrata da Duma." (LÊNIN, [26/02/1910], III, p. 372) 
Lênin comemora que tanto Plekhanov, pela direita, como o grupo Vperiod, pela esquerda, na segunda metade de 1909, tenham reconhecido a importância do fortalecimento do partido. Mesmo assim, Lênin chamava atenção para dois "desvios" que podiam se manifestar. Um deles implicava a ideia a subestimação do papel do partido e o desprezo pela luta ilegal; a outra dizia respeito à subestimação do trabalho legal, em particular em relação à Duma.

$\mathrm{Na}$ verdade, os identificáveis como expressão desses “desvios” pensavam priorizar o trabalho intelectual. A direita se aproxima do liberalismo a fim de estimular o constitucionalismo e a esquerda entende que a educação socialista da classe operária e a criação de uma cultura proletária seria o verdadeiro fundamento da revolução.

Passado mais um ano, Lênin já se sente em condições da avaliar todo o período iniciado em 1905, com a revolução. Assinala que

A dialética do desenvolvimento histórico foi tal que, no primeiro período, se colocava na ordem do dia a realização de transformações imediatas em todos os ambitos da vida do País, e, no segundo, que os mais vastos setores estudaram a experiência adquirida, assimilaram e penetraram, se é licito expressar-se assim, no subsolo, nas filas atrasadas das diferentes classes. (LÊENIN, III, p. 410)

No decorrer desse conjunto de mudanças, na vida social e na ideologia, é que o marxismo teria enfrentado uma grave crise e desagregação. A defesa intransigente dos fundamentos do marxismo se pos então na ordem do dia e assim se fez necessária a luta contra os revisionismos. De um lado contra aqueles que criticavam os fundamentos filosóficos do materialismo "na forma de uma epidemia machista" (relativo a Mach) e por outro lado o espírito de apostasia que abraçou o liberalismo burguês. (KRAUSZ, 2017, p.411)

\section{Nova unidade, novo partido}

Em janeiro de 1911, Bogdánov se afastou definitivamente do partido, mas persistiu na atividade de educar a classe operária para a nova civilização socialista que haveria de vir. Bogdánov, entregue às suas atividades de divulgação cientifica, em 1914, insistia que a criação de uma cultura proletária continuava a ser a tarefa imediata dos bolcheviques na questão da "hegemonia cultural da classe operária.” (apud KRAUSZ, 2017, p. 189)

Começava também uma nova fase de avanço do movimento popular, que pode ser demarcado por dois acontecimentos próximos: o assassinato do ministro Stolopyn por uma socialista revolucionário, em setembro de 1911, e a ruptura definitiva entre bolcheviques e mencheviques. De fato, em janeiro de 1912, na cidade de Praga, a conferência dos bolcheviques decidiu assumir que os bolcheviques e só eles eram o POSDR. Como seu novo porta-voz foi organizado o jornal Pravda. Os problemas relativos ao partido estavam aparentemente resolvidos e os bolcheviques poderiam agora estar mais bem preparados para os próximos embates, mas isso não significa que novas 
diferenças surgissem no interior da organização, algo inteiramente previsível considerado ser esse um fenômeno constitutivo de um partido revolucionário.

\section{Referências:}

KRAUSZ, Tamàs. Reconstruindo Lênin: uma biografia intelectual. São Paulo: Boitempo, 2017.

LENIN, Vladimir. Dos tácticas de la socialdemocracia em la revolucion democrática. In: LENIN, Vladimir. Obras escogidas en doce tomos. Moscu: Editorial Progreso, tomo III, 1976, p. 01-124.

LENIN, Vladimir. Marxismo y revisionismo. In: Obras escogidas en doce tomos. Moscu: Editorial Progreso, tomo III, 1976, p. 298-307.

LENIN, Vladimir. Em ruta In: Obras escogidas en doce tomos. Moscu: Editorial Progreso, tomo III, 1976, p. 348-357.

LENIN, Vladimir. Hacia la unidad. In: Obras escogidas en doce tomos. Moscu: Editorial Progreso, tomo III, 1976, p. 370-378.

LENIN, Vladimir. Alcunas particularidades del dessarollo histórico del marxismo. In: Obras escogidas en doce tomos. Moscu: Editorial Progreso, tomo III, 1976, p. 407-412.

LENIN, Vladimir. Materialismo y empirocriticismo. In: Obras escogidas en doce tomos. Moscu: Editorial Progreso, tomo IV, p. 01-365.

PLEKHANOV, G. Questões fundamentais do marxismo. Rio de Janeiro: Editorial Vitória, 1956.

SCHERRER, Jutta. Bogdánov e Lenin: il bolscevismo al bívio In: Storia del Marxismo (a cura di Eric Hobsbawn et all). Torino: Giulio Einaudi Editore, tomo II, vol. 1, 1979, p. 493-526.

STRADA, Vitório. La polemica tra bolscevichi e menscevichi sulla rivoluzione di 1905 In: Storia del Marxismo (a cura di Erica Hobsbawn et all). Torino: Giulio Einaudi Editore, tomo II, vol. 1, 1979, p. 441-492.

STRUVE, Piotr. B. et all. La svolta - Vechi: la intelligencija russa tra il 1905 e il 1909. Milano: Jaca Book, 2 ed., 1990.

TOLEDO, Pedro Ramos de. Estrela Vermelha: um estudo político econômico da primeira utopia literária soviética. São Paulo: Universidade de São Paulo, Dissertação de Mestrado em História Econômica, 2019.

\footnotetext{
Notas

1 Pós-doutor em Política Internacional (1999) pela Facoltà di Scienze Politiche da Università Statale di Milano, em Filosofia do Direito na Università di Roma Tre (2006)e Filosofia Política na Università Statale di Bologna (2011). É Professor Titular em Ciências Políticas na Faculdade de Filosofia e Ciências da UNESP (campus de Marilia). Líder do grupo Cultura e Política do Mundo do Trabalho: http://dgp.cnpq.br/dgp/espelhogrupo/20544. Currículo Vitae Plataforma Lattes: http://lattes.cnpq.br/1034829852338994. Orcid: http://orcid.org/0000-0003-3276-8789. E-mail: delroio@terra.com.br
} 